\title{
Effects of estrogen on higher-order cognitive functions in unstressed human females may depend on individual variation in dopamine baseline levels
}

\section{Lorenza S. Colzato* and Bernhard Hommel}

Institute for Psychological Research and Leiden Institute for Brain and Cognition, Leiden University, Leiden, Netherlands

*Correspondence: colzato@fsw.leidenuniv.nl

Edited by:

Belinda Pletzer, University of Salzburg, Austria

Reviewed by:

Emily Goard Jacobs, Harvard Medical School, USA

Belinda Pletzer, University of Salzburg, Austria

Keywords: estrogen, cognition, dopamine, individual differences, "inverted-U"-shaped function

\section{INTRODUCTION}

The gonadal steroid hormone estrogen (i.e., estradiol) seems to modulate higher order cognitive processes driven by dopamine (DA) such as learning, reward processing, working memory (WM), and inhibitory control (Hampson, 1990a,b; Maki et al., 2002; Caldu and Dreher, 2007; Dreher et al., 2007; Gasbarri et al., 2008; Colzato et al., 2010, 2012; Jacobs and D'Esposito, 2011). However, it is important to note that sex steroid hormones have been shown to impact several other neurotransmitter systems, including gamma-aminobutyric acid (GABA). Indeed, in healthy women the cortical GABA levels declines from the follicular phase (FP) to the mid luteal and late luteal phases (Epperson et al., 2002). In a recent review, Sinclair et al. (2014) suggested that the adolescent brain is shaped by the interaction between estrogen and glucocorticoids with a specific impact on DA neurotransmission. The focus of the present opinion article is not on glucocorticoid-estrogen interactions but on estrogen effects on higherorder cognition in unstressed human females.

High levels of estradiol are accompanied by increases in the attentional blink (Hollander et al., 2005) and in interference in the Stroop color-word task (Hatta and Nagaya, 2009), indicating reduced cognitive control. Moreover, the reactivity of the reward system is augmented in women during the midfollicular phase when estrogen is unopposed by progesterone (Dreher et al., 2007).
Previous studies have shown that gender differences in DA-modulated higherorder cognitive processes are restricted to a particular phase of the female menstrual cycle: the late FP, in which the estrogen level is high. Growing evidence suggests that the dopaminergic system seems to be particularly strongly affected by estrogen. After estrogen enters the brain, it is converted into cathecol estrogen, which has been considered to inhibit the catechol Omethyltransferase (Ball et al., 1972), an enzyme responsible for the degradation of DA in prefrontal cortex (PFC). Several studies have pointed out that the estrous cycle is related to augmentation in DA release associated with high levels of estrogen in rodents (Di Paolo et al., 1986; Becker et al., 2001; Dazzi et al., 2007; for review see Becker, 1999) and in monkeys (Czoty et al., 2009). Moreover, as pointed out by Czoty et al. (2009), receptor autoradiography studies have revealed that D2 receptor densities can raise in the presence of natural elevations in estrogen during the estrous cycle and after exogenous estrogen administration (Pazos et al., 1985; Di Paolo et al., 1988; Bazzett and Becker, 1994; Becker, 1999; see Di Paolo, 1994).

Interestingly, the ventral tier of the midbrain sends its DA projections to the dorsal and lateral parts of the PFC, while the dorsal tier sends its DA projections primarily to the ventral striatum, which projects strongly to ventrolateral and ventromedial PFC (Cools, 2006). As suggested by Miller (2000), reward information may be mediated by the dopamine-mediated innervation of PFC from a group of cells situated in the midbrain ventral tegmental area (VTA). Inhibitory control of behavior and thoughts seems to be driven by the frontal/basal-ganglia system. Finally, DA levels in PFC are related to the maintenance of WM information (Cools, 2006). Given these links between estrogen, DA, and PFC, it should not be surprising that $\mathrm{PFC}$-depending functions, like inhibitory control, WM, and reward processing, are particularly affected by the menstrual cycle.

\section{INDIVIDUAL BASELINE LEVELS OF DA MAY EXHIBIT DIFFERENTIAL SENSITIVITY TO ESTROGEN}

In some previous studies, estrogen seems to have modulated cognitive processes in opposite directions or in unreliable ways. For example, studies have found improved verbal working memory (Rosenberg and Park, 2002) and better performance on a test of implicit memory (Maki et al., 2002) when the estrogen level was high, while others found high levels of estrogen to have a negative effect on delayed matching-to-sample working memory task (Gasbarri et al., 2008). Jacobs and D'Esposito (2011) were the first to suggest that inconsistencies in the literature linking WM and estrogen (Maki et al., 2002; Rosenberg and Park, 2002; Gasbarri et al., 2008) may be explained by taking baseline levels of DA into account. Indeed, these authors showed that the direction of the effect estrogen has on WM depends on indices of baseline DA (as assessed by the genetic variability associated with the COMT Val ${ }^{158}$ Met genotype). 
We suggest that not only for WM, but for all cognitive processes related to DA, the effect of estrogen might depend on individual variation in baseline DA function, which follows an "Inverted-U"shaped function. Indeed, neurotransmitters such as DA often relate to performance in a nonlinear fashion, with the best performance related to a medium level, while higher levels are likely to be counterproductive (Muly et al., 1998; Goldman-Rakic et al., 2000). This effect is explained by the existence of GABAergic interneurons with D1 receptors and inhibitory input to cortical pyramidal cells, which are related to cognitive performance. At moderate levels of dopamine release the function of these pyramidal cells (but not of the interneurons) is enhanced, which leads to better performance as compared to lower levels. But at high levels of dopamine release, the GABAergic inhibitory interneurons also get excited and start projecting the neurotransmitter GABA onto the pyramidal cortical cells. This provides them with inhibitory input, leading to impaired performance (Goldman-Rakic et al., 2000). Consistent with this picture, the impact of most dopaminergic agonist drugs is modulated by individual differences: increasing the dopamine level is likely to be beneficial for individuals whose level falls short of the optimal level but to impair the performance of individuals with medium (optimal) or high levels (Cools, 2006).

We speculate that different individuals may have different baseline levels of DA and may therefore exhibit differential sensitivity to the positive and negative effects of estrogen. Given that estrogen is associated with higher DA turnover rates, if estrogen affects the DA functioning in driving a particular cognitive function, we would expect a cognitive beneficial effect in the late FP (i.e., with the highest level of estrogen) for individuals with a low DA baseline level. In contrast, we would expect a cognitive detrimental effect in the late FP for individuals with an already optimal baseline level. That is, low baseline levels of DA, which are in general accompanied by poor cognitive performance, may be improved by high levels of estrogen. In contrast, high baseline levels of DA, commonly related to good cognitive performance, may be impaired by estrogen.
Colzato and colleagues showed, in two independent samples, that late FP was associated with both less efficient inhibitory output control (Colzato et al., 2010) and more efficient inhibitory input control (Colzato et al., 2012). Of course, we cannot exclude that this dissociation simply reflected the independence of input and output control (Johnston et al., 1995). However, if our idea that the effect of estrogen on all DA-driven cognitive processes depends on individual variation in baseline DA is correct, it is a real possibility that individual differences have modulated our previous findings. If so, it is reasonable to assume that our first study (Colzato et al., 2010) tapped a sample with an already optimal DA baseline level while the second (Colzato et al., 2012) happened to assess a sample with low DA baseline levels.

\section{MARKERS OF DA BASE LEVELS}

The direct assessment of DA function in humans is only possible by means of positron emission tomography (PET) so far, which is, however, very expensive and highly invasive due to radioactive contamination and arterial blood sampling (Volkow et al., 2009). An ideal index of DA base levels, also used by Jacobs and D'Esposito (2011), is genetic variability related to levels of DA, which is nonetheless still a costly procedure.

Interestingly, DA can be found in high concentration in the amacrine and interplexiform cells of the retina (BodisWollner and Tzelepi, 1998; Witkovsky, 2004). Abnormal color discrimination has been reported for several neuropsychiatric conditions underlying al dopaminergic functions, such as Parkinson's and Huntington's disease, Tourette syndrome, ADHD, and cocaine use (Paulus et al., 1993; Pieri et al., 2000; Melun et al., 2001; Tannock et al., 2006; Hulka et al., 2013). Roy et al. (2003) suggested that color vision impairment points to a central hypodopaminergic state. Very recently, color vision has been found to predict the efficiency in resolving response conflict given that both are driven by dopamine (Colzato et al., under revision). This raises the possibility that individual color discrimination performance predicts individual differences in sensitivity to the positive (i.e., enhancing) and negative (i.e., unfavorable) effects of estrogen. For example in tasks assessing cognitive control and adaptation one would expect benefits (e.g., better goal regulation in the face of response conflict) in the late FP for individuals with poor color discrimination but a detrimental effect (e.g., poorer goal regulation) in individuals with optimal color discrimination.

Another interesting measure of DA functioning is the spontaneous eyeblink rate (EBR), a well-established clinical indicator (Karson, 1983; Shukla, 1985; Blin et al., 1990; Taylor et al., 1999). Patients with DA-related dysfunction show atypical patterns: EBRs are elevated in in schizophrenia patients (Freed, 1980) but reduced in recreational cocaine users (Colzato et al., 2008b) and Parkinson's patients (Deuschel and Goddemeier, 1998). Moreover, pharmacological studies in nonhuman primates and humans have shown that DA agonists, such as apomorphine, and antagonists increase and decrease EBRs, respectively, (Blin et al., 1990; Kleven and Koek, 1996). Similarly to color vision, EBR has also been found to predict DA-driven cognitive processes (e.g., Dreisbach et al., 2005; Colzato et al., 2007, 2008a, 2009). Accordingly, EBR, in interaction with the individual genetic setup, should predict individual differences in sensitivity to the positive and negative effects of estrogen. In particular, we would expect cognitive benefits in the late FP for individuals with low EBR but impairments in individuals with an average/high EBR.

It might be particularly informative to use proton magnetic resonance spectroscopy (1H-MRS) and plasma levels of homovanillic acid (HVA) to trace the impact of estrogen on the DA system. $1 \mathrm{H}$-MRS permits to measure the concentration of particular chemicals, based on subtle differences in the resonance of the protons they contain. This technique has been successfully applied in the past to reflect changes in dopamine pathways (Moore et al., 2006) and to investigate the effect of dopaminergic treatment on the cortex (Lucetti et al., 2007). In contrast to PET, 1H-MRS does not use invasive radioactive tracers and it is way less expensive. 1H-MRS allows measuring brain metabolites including creatine $(\mathrm{Cr})$, inositol (Ino), and glutamate and 
glutamine (Glx), and the ratio between them. Because protons experience different shielding effects from the surrounding electrons in different molecules, their resonance varies from one type of molecule to another. In the late FP we would expect increased brain DA and, accordingly, a modulation of the Glx-to-Cr and Glx-toIno ratio.

Homovanillic acid (HVA) is a metabolite of DA which is typically decreased in repetitive behavior disorders (Lewis et al., 1996) and it may be altered in in disorders of catecholamine metabolism. For example, monamine oxidase-A deficiency can cause decreased HVA values, while a deficiency of dopamine beta-hydrolase (the enzyme that converts dopamine to norepinephrine) can cause elevated HVA concentrations. Accordingly, HVA values should predict individual differences in sensitivity to the positive and negative effects of estrogen. In particular, we would expect cognitive benefits in the late FP for individuals with low HVA values but impairments in individuals with an average/high HVA values.

\section{SUMMARY}

We propose that future studies investigating the effect of estrogen on DAdriven higher order cognitive processes should take into account individual differences in DA base levels. The existing research on the role of estrogen in higher order cognitive processes has been mainly "effect"-driven, and thus only shown that estrogen can have an effect without explaining how it modulates cognitive processes and why some people benefit more than others. To get a better understanding of the underlying mechanism and the interplay between estrogen, dopaminergic supply, and cognitive functioning it is mandatory to develop a comprehensive, detailed model of how estrogen modulates higher order cognitive processes in healthy humans.

\section{ACKNOWLEDGMENTS}

This work was supported by research grant from the Netherlands Organization for Scientific Research (NWO) awarded to Lorenza S. Colzato (Vidi grant: \#452-12001).

\section{REFERENCES}

Ball, P., Knuppen, R., Haupt, M., and Breuer, H. (1972). Interactions between estrogens and catecholamines. Studies on the methylation of catechol estrogens, catechol amines and other catechols by the catechoI-O-methyltransferase of human liver. J. Clin. Endocrinol. Metab. 34, 736-746. doi: 10.1210/jcem-34-4-736

Bazzett, T. J., and Becker, J. B. (1994). Sex differences in the rapid and acute effects of estrogen on striatal D2 dopamine receptor binding. Brain Res. 637, 163-172. doi: 10.1016/0006-8993(94)91229-7

Becker, J. B. (1999). Gender differences in dopaminergic function in striatum and nucleus accumbens. Pharmacol. Biochem. Behav. 64, 803-812. doi: 10.1016/S0091-3057(99)00168-9

Becker, J. B., Molenda, H., and Hummer, D. L. (2001). Gender differences in the behavioral responses to cocaine and amphetamine. Implications for mechanisms mediating gender differences in drug abuse. Ann. N. Y. Acad. Sci. 937, 172-187. doi: 10.1111/j.1749-6632.2001.tb03564.x

Blin, O., Masson, G., Azulay, J. P., Fondarai, J., and Serratrice, G. (1990). Apomorphine-induced blinking and yawning in healthy volunteers. $\mathrm{Br}$. J. Clin. Pharmacol. 30, 769-773. doi: 10.1111/j.13652125.1990.tb03848.x

Bodis-Wollner, I., and Tzelepi, A. (1998). The pushpull action of dopamine on spatial tuning of the monkey retina: the effects of dopaminergic deficiency and selective D1 and D2 receptor ligands on the pattern electroretinogram. Vis. Res. 38, 1479-1487. doi: 10.1016/S0042-6989(98) 00028-5

Caldu, X., and Dreher, J.-C. (2007). Hormonal and genetic influences on processing reward and social information. Ann. N. Y. Acad. Sci. 1118, 43-73. doi: 10.1196/annals.1412.007

Colzato, L. S., Hertsig, G., van den Wildenberg, W., and Hommel, B. (2010). Estrogen modulates inhibitory control in healthy human females: evidence from the stop-signal paradigm. Neuroscience 167, 709-715. doi: 10.1016/j.neuroscience. 2010. 02.029

Colzato, L. S., Pratt, J., and Hommel, B. (2012). Estrogen modulates inhibition of return in healthy human females. Neuropsychologia 50, 98-103. doi: 10.1016/j.neuropsychologia.2011.11.003

Colzato, L. S., Slagter, H. A., Spapé, M. A., and Hommel, B. (2008a). Blinks of the eye predict blinks of the mind. Neuropsychologia 46, 3179-3183. doi: 10.1016/j.neuropsychologia.2008. 07.006

Colzato, L. S., van den Wildenberg, W. P. M., and Hommel, B. (2008b). Reduced spontaneous eye blink rates in recreational cocaine users: evidence for dopaminergic hypoactivity. PLoS ONE 2:e1143. doi: 10.1371/journal.pone.0001143

Colzato, L. S., van den Wildenberg, W. P. M., van Wouwe, N. C., Pannebakker, M. M., and Hommel, B. (2009). Dopamine and inhibitory action control: evidence from spontaneous eye blink rates. Exp. Brain Res. 196, 467-474. doi: 10.1007/s00221009-1862-x

Colzato, L. S., van Wouwe, N. C., and Hommel, B. (2007). Spontaneous eyeblink rate predicts the strength of visuomotor binding. Neuropsychologia 45, 2387-2392. doi: 10.1016/j.neuropsychologia. 2007.03.004
Cools, R. (2006). Dopaminergic modulation of cognitive function: Implication for L-DOPA therapy in Parkinson's disease. Neurosci. Biobehav. Rev. 30, 1-34. doi: 10.1016/j.neubiorev.2005. 03.024

Czoty, P. W., Riddick, N. V., Gage, H. D., Sandridge, M., Nader, S. H., Garg, S., et al. (2009). Effect of menstrual cycle phase on dopamine D2 receptor availability in female cynomolgus monkeys. Neuropsychopharmacology 34, 548-554. doi: 10.1038/npp. 2008.3

Dazzi, L., Seu, E., Cherchi, G., Barbieri, P. P., Matzeu, A., and Biggio, G. (2007). Estrus cycledependent changes in basal and ethanol-induced activity of cortical dopaminergic neurons in the rat. Neuropsychopharmacology 32, 892-901. doi: 10.1038/sj.npp.1301150

Deuschel, G., and Goddemeier, C. (1998). Spontaneous and reflex activity of facial muscles in dystonia, Parkinson's disease, and in normal subjects. J. Neurol. Neurosurg. Psychiatry 64, 320-324. doi: 10.1136/jnnp.64.3.320

Di Paolo, T. (1994). Modulation of brain dopamine transmission by sex steroids. Rev. Neurosci. 5, 27-41. doi: 10.1515/REVNEURO.1994.5.1.27

Di Paolo, T., Falardeau, P., and Morissette, M. (1988). Striatal D2 dopamine agonist binding sites fluctuate during the rat estrous cycle. Life Sci. 43, 655-672. doi: 10.1016/0024-3205(88) 90137-3

Di Paolo, T., Levesque, D., and Daigle, M. (1986). A physiological dose of progesterone affects rat striatum biogenic amine metabolism. Eur. J. Pharmacol. 125, 11-16. doi: 10.1016/00142999(86)90077-4

Dreher, J.-C., Schmidt, P. J., Kohn, P., Furman, D., Rubinow, D., and Berman, K. F. (2007). Menstrual cycle phase modulates reward-related neural function in women. Proc. Natl. Acad. Sci. U.S.A. 104, 2465-2470. doi: 10.1073/pnas. 0605569104

Dreisbach, G., Müller, J., Goschke, T., Strobel, A., Schulze, K., Lesch, K., et al. (2005). Dopamine and cognitive control: the influence of spontaneous eyeblink rate and dopamine gene polymorphisms on perseveration and distractibility. Behav. Neurosci. 119, 483-490. doi: 10.1037/07357044.119.2.483

Epperson, C. N., Haga, K., Mason, G. F., Sellers, E., Gueorguieva. R., Zhang, W., et al. (2002). Cortical gamma-aminobutyric acid levels across the menstrual cycle in healthy women and those with premenstrual dysphoric disorder: a proton magnetic resonance spectroscopy study. Arch. Gen. Psychiatry 59, 851-858. doi: 10.1001/archpsyc.59.9.851

Freed, W. (1980). Eye-blink rates and platelet monoamine oxidase activity in chronic schizophrenic patients. Biol. Psychiatry 15, 329-332.

Gasbarri, A., Pompili, A., d'Onofrio, A., Cifariello, A., Tavares, M. C., and Tomaz, C. (2008). Working memory for emotional facial expressions: role of the estrogen in young women. Psychoneuroendocrinology 33, 964-972. doi: 10.1016/j.psyneuen.2008.04.007

Goldman-Rakic, P. S., Muly, E. C. III., and Williams, G. V. (2000). D1 receptors in prefrontal cells and circuits. Brain Res. Rev. 31, 295-301. doi: 10.1016/S0165-0173(99)00045-4 
Hampson, E. (1990a). Estrogen related variations in human spatial and articulatory-motor skills. Psychoneuroendocrinology 15, 97-111. doi: 10.1016/0306-4530(90)90018-5

Hampson, E. (1990b). Variations in sex related cognitive abilities across the menstrual cycle. Brain Cogn. 14, 26-43. doi: 10.1016/0278-2626(90) 90058-V

Hatta, T., and Nagaya, K. (2009). Menstrual cycle phase effects on memory and Stroop task performance. Arch. Sex. Behav. 38, 821-827. doi: 10.1007/s10508-008-9445-7

Hollander, A., Hausmann, M., Hamm, J. P., and Corballis, M. C. (2005). Sex hormonal modulation of hemispheric asymmetries in the attentional blink. J. Int. Neuropsychol. Soc. 11, 263-272. doi: 10.1017/S1355617705050319

Hulka, L. M., Wagner, M., Preller, K. H., Jenni, D., and Quednow, B. B. (2013). Blue-yellow color vision impairment and cognitive deficits in occasional and dependent stimulant users. Int. J. Neuropsychopharmacol. 16, 535-547. doi: 10.1017/S1461145712000624

Jacobs, E., and D'Esposito, M. (2011). Estrogen shapes dopamine-dependent cognitive processes: implications for women's health. J. Neurosci. 31, 5286-5293. doi: 10.1523/JNEUROSCI.639410.2011

Johnston, J. C., McCann, R. S., and Remington, R. W. (1995). Chronometric evidence for two types of attention. Psychol. Sci. 6, 365-369. doi: 10.1111/j.1467-9280.1995.tb00527.x

Karson, C. N. (1983). Spontaneous eye-blink rates and dopaminergic systems. Brain 106, 643-653. doi: 10.1093/brain/106.3.643

Kleven, M. S., and Koek, W. (1996). Differential effects of direct and indirect dopamine agonists on eye blink rate in cynomolgus monkeys. J. Pharmacol. Exp. Ther. 279, 1211-1219.

Lewis, M. H., Bodfish, J. W., Powell, S. B., Wiest, K., Darling, M., and Golden, R. N. (1996). Plasma HVA in adults with mental retardation and stereotyped behavior: biochemical evidence for a dopamine deficiency model. Am. J. Ment. Retard. 100, 413-427.

Lucetti, C., DelDotto, P., Gambaccini,G., Ceravolo,R., Logi, C., Berti, C., et al. (2007). Influences of dopaminergic treatment on motor cortex in Parkinson disease: a MRI/MRS study. Mov. Disord. 22, 2170-2175. doi: 10.1002/mds.21576
Maki, P. M., Rich, J. B., and Rosenbaum, R. S. (2002). Implicit memory varies across the menstrual cycle: estrogen effects in young women. Neuropsychologia 40, 518-529 doi: 10.1016/S00283932(01)00126-9

Melun, J. P., Morin, L. M., Muise, J. G., and DesRosiers, M. (2001). Color vision deficiencies in Gilles de la Tourette syndrome. J. Neurol. Sci. 186, 107-110. doi: 10.1016/S0022-510X(01)00516-0

Miller, E. K. (2000). The prefrontal cortex and cognitive control. Nat. Rev. Neurosci. 1, 59-65. doi: $10.1038 / 35036228$

Moore, C. M., Biederman, J., Wozniak, J., Mick, E., Aleardi, M., Wardrop, M., et al. (2006). Differences in brain chemistry in children and adolescents with attention deficit hyperactivity disorder with and without comorbid bipolar disorder: a proton magnetic resonance spectroscopy study. Am. J. Psychiatry 163, 316-318. doi: 10.1176/appi.ajp.163.2.316

Muly, E. C. III., Szigeti, K., and Goldman-Rakic, P. S. (1998). D1 receptor in interneurons of macaque prefrontal cortex: distribution and subcellular localization. J. Neurosci. 18, 10553-10565.

Paulus, W., Schwarz, G., Werner, A., Lange, H., Bayer, A., Hofschuster, M., et al. (1993). Impairment of retinal increment thresholds in Huntington's disease. Ann. Neurol. 34, 574-578. doi: 10.1002/ana.410340411

Pazos, A., Stoeckel, M. E., Hindelang, C., and Palacios, J. M. (1985). Autoradiographic studies on dopamine D2 receptors in rat pituitary: influence of hormonal states. Neurosci. Lett. 59, 1-7. doi: 10.1016/0304-3940(85)90206-X

Pieri, V., Diederich, N. J., Raman, R., and Goetz, C. G. (2000). Decreased color discrimination and contrast sensitivity in Parkinson's disease. J. Neurol. Sci. 172, 7-11. doi: 10.1016/S0022510X(99)00204-X

Rosenberg, L., and Park, S. (2002). Verbal and spatial functions across the menstrual cycle in healthy young women. Psychoneuroendocrinology 27, 835-841. doi: 10.1016/S0306-4530(01) 00083-X

Roy, A., Roy, M., Berman, J., and Gonzalez, B. (2003). Blue cone electroretinogram amplitudes are related to dopamine function in cocainedependent patients. Psychiatry Res. 117, 191-195. doi: 10.1016/S0165-1781(02)00323-2
Shukla, D. (1985). Blink rate as clinical indicator. Neurology 35:286. doi: 10.1212/WNL.35.2.286

Sinclair, D., Purves-Tyson, T. D., Allen, K. M., and Weickert, C. S. (2014). Impacts of stress and sex hormones on dopamine neurotransmission in the adolescent brain. Psychopharmacology 231, 1581-1599. doi: 10.1007/s00213-013-3415-z

Tannock, R., Banaschewski, T., and Gold, D. (2006). Color naming deficits and attentiondeficit/hyperactivity disorder: a retinal dopaminergic hypothesis. Behav. Brain Funct. 2:4. doi: 10.1186/1744-9081-2-4

Taylor, J. R., Elsworth, J. D., Lawrence, M. S., Sladek, J. R., Roth, R. H., and Redmond, D. E. Jr. (1999). Spontaneous blink rates correlate with dopamine levels in the caudate nucleus of MPTPtreated monkeys. Exp. Neurol. 158, 214-220. doi: 10.1006/exnr.1999.7093

Volkow, N. D., Fowler, J. S., Wang, G. J., Baler, R., and Telang, F. (2009). Imaging dopamine's role in drug abuse and addiction. Neuropharmacology 56, 3-8. doi: 10.1016/j.neuropharm.2008. 05.022

Witkovsky, P. (2004). Dopamine and retinal function. Doc. Ophthalmol. 108, 17-40. doi: 10.1023/B:DOOP.0000019487.88486.0a

Conflict of Interest Statement: The authors declare that the research was conducted in the absence of any commercial or financial relationships that could be construed as a potential conflict of interest.

Received: 13 January 2014; accepted: 19 March 2014; published online: 07 April 2014.

Citation: Colzato LS and Hommel B (2014) Effects of estrogen on higher-order cognitive functions in unstressed human females may depend on individual variation in dopamine baseline levels. Front. Neurosci. 8:65. doi: 10.3389/fnins.2014.00065

This article was submitted to Neuroendocrine Science, a section of the journal Frontiers in Neuroscience.

Copyright (c) 2014 Colzato and Hommel. This is an open-access article distributed under the terms of the Creative Commons Attribution License (CC BY). The use, distribution or reproduction in other forums is permitted, provided the original author(s) or licensor are credited and that the original publication in this journal is cited, in accordance with accepted academic practice. No use, distribution or reproduction is permitted which does not comply with these terms. 